
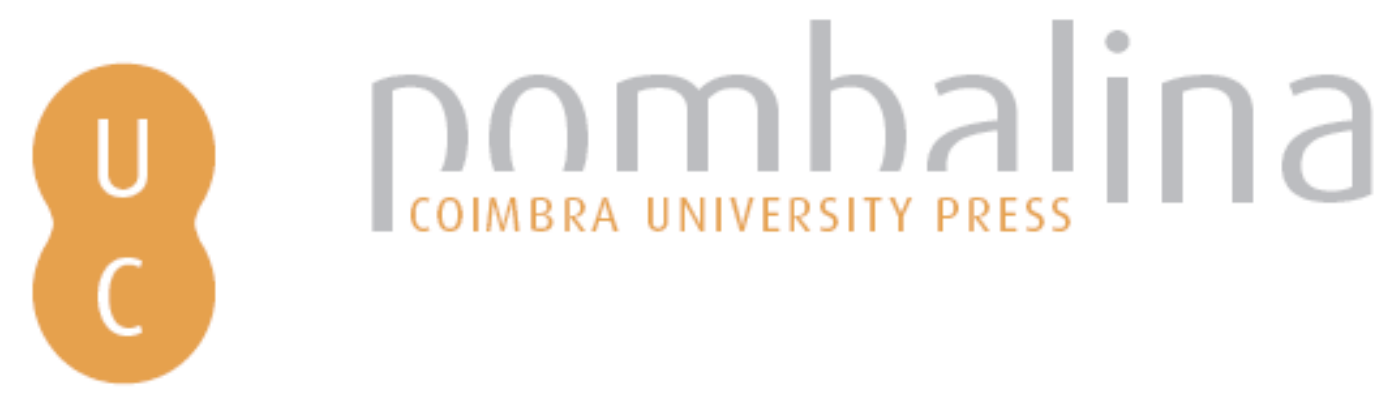

\title{
"Nôtre Grand Dessein": o projeto de casamento entre o Duque Vítor Amadeu e a Infanta Isabel Luísa e a política dinástica dos Sabóias (1675-82)
}

\author{
Autor(es): Osborne, Toby \\ Publicado por: Imprensa da Universidade de Coimbra \\ URL \\ persistente: URI:http://hdl.handle.net/10316.2/32352 \\ DOI: $\quad$ DOI:http://dx.doi.org/10.14195/978-989-26-0604-0_6 \\ Accessed : $\quad$ 26-Apr-2023 12:16:53
}

A navegação consulta e descarregamento dos títulos inseridos nas Bibliotecas Digitais UC Digitalis, UC Pombalina e UC Impactum, pressupõem a aceitação plena e sem reservas dos Termos e Condições de Uso destas Bibliotecas Digitais, disponíveis em https://digitalis.uc.pt/pt-pt/termos.

Conforme exposto nos referidos Termos e Condições de Uso, o descarregamento de títulos de acesso restrito requer uma licença válida de autorização devendo o utilizador aceder ao(s) documento(s) a partir de um endereço de IP da instituição detentora da supramencionada licença.

Ao utilizador é apenas permitido o descarregamento para uso pessoal, pelo que o emprego do(s) título(s) descarregado(s) para outro fim, designadamente comercial, carece de autorização do respetivo autor ou editor da obra.

Na medida em que todas as obras da UC Digitalis se encontram protegidas pelo Código do Direito de Autor e Direitos Conexos e demais legislação aplicável, toda a cópia, parcial ou total, deste documento, nos casos em que é legalmente admitida, deverá conter ou fazer-se acompanhar por este aviso.

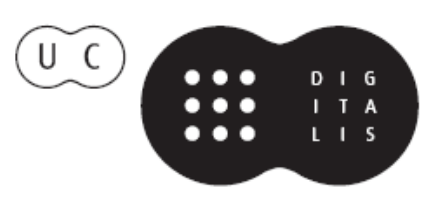




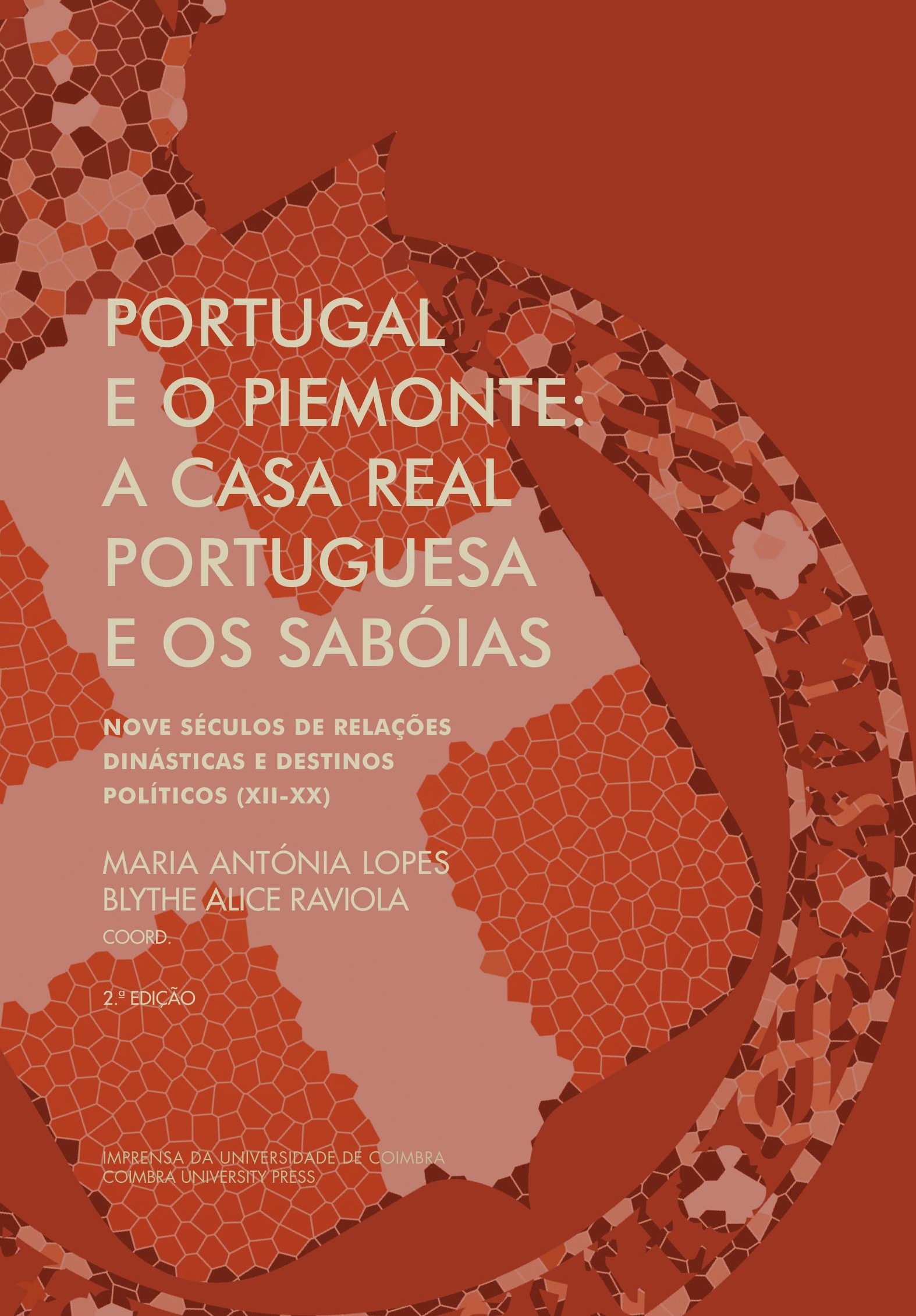


Toby Osborne

University of Durham, U.K.

\section{“NÔTRE GRAND DESSEIN": \\ O PROJECTO DE CASAMENTO ENTRE O DUQUE VÍTOR AMADEU E A INFANTA ISABEL LUísa e a POLítica DiNÁstica dos SABóias (1675-82)}

A 22 de Março de 1681, depois de extenuantes negociações sobre os termos exactos dos vinte artigos do contrato matrimonial, o duque Vítor Amadeu II de Sabóia (1666-1732) e a infanta portuguesa Isabel Luísa (1669-1690) ficaram formalmente noivos durante uma cerimónia pública em Lisboa. O duque de Sabóia estava representado pelo embaixador extraordinário, o marquês de Dronero, assim como por um séquito de cento e trinta pessoas, diante das quais se realizaram as celebrações oficiais em Turim e na capital portuguesa. A 20 de Junho de 1682 uma pequena frota de doze navios portugueses atracou no porto saboiano de Nice-Villefranche para conduzir o duque a Lisboa, na plena expectativa de que o projecto nupcial fosse respeitado, para afinal voltar, em Outubro seguinte, meio vazia. O embaraçoso regresso da frota marcou o fim de um processo que principiara em $1675^{1}$. Vítor Amadeu II, segundo as informações fornecidas à delegação portuguesa comandada pelo duque de Cadaval, encontrava-se impossibilitado de partir por causa de uma indisposição. Apesar da questão da data da jornada ter sido longamente debatida durante os preparativos

\footnotetext{
* Tradução do Inglês de Maria Antónia Lopes.
}

Agradeço ao Dr. Davide De Franco a reprodução de parte da série "Lettere Ministri, Portogallo"

${ }^{1}$ Remonta a essa altura a primeira alusão mútua ao casamento, ainda antes da morte de Carlos Manuel II, que teve lugar em Junho de 1675. Cf. Cfr. ASTo, Corte, MPRI, Matrimoni, m. 32, fasc. 9, Maria Francisca Isabel a Madame Real, 18 de Março de 1675; resposta de 2 de Maio de 1675. 
logísticos em Portugal, e enquanto se esperava que pudesse empreender a viagem logo que melhorasse e o Inverno tivesse passado, ele ficou no Piemonte. No fim de Dezembro de 1682 o projecto nupcial foi declarado desfeito com base nas más notícias transmitidas por Cadaval a Lisboa sobre o deplorável estado de saúde de Vítor Amadeu II. Exprimindo amargura, o governo de Turim mostrava-se disposto a censurar Cadaval:

"Madame Real [Maria Joana Baptista] reuniu o Conselho e pediu a S.A.R. [Vítor Amadeu II] autorização para dissolver o seu casamento, considerando contrário à sua dignidade e à sua segurança sustentá-lo e contraí-lo depois das injuriosas insinuações que Cadaval proferiu contra a sua pessoa... e eis a anulação do contrato. Toda a Europa que dele é espectadora ajuizará entre nós e Portugal, e muito espero que a 'fides Lusitana' não se torne proverbial como a 'fides punica'. S.A.R. encontrará maneira de recuperar o coração dos seus súbditos, tendo embora perdido a esperança de um Reino."²

Muito compreensivelmente, o episódio foi envolvido em mistério. Dados os preparativos para a viagem, parece que, pelo menos até ao momento da partida, o duque de Sabóia tinha realmente tenções de se deslocar a Portugal ${ }^{3}$. Talvez Vítor Amadeu II estivesse na realidade demasiado doente para viajar. Mas se tinha gozado de pouca saúde durante a infância, decerto que se restabeleceu depressa depois da partida de Cadaval: sabe-se que no início de Novembro participou numa missa pública em Turim, com a mãe, como sinal da sua recuperação, aparecendo aos seus súbditos alegres "maior e mais forte do que antes da doença" ${ }^{4}$. Ter-se-ia tratado, então, de

2 ASTo, Corte, MPRE, Lettere Ministri, Portogallo, m. 2, fasc. 1, 142, De la Torre a Gubernatis, 29 de Dezembro de 1682. Veja-se também ASTo, Corte, MPRI, Matrimoni, m. 32, fasc. 47, De la Torre a Gubernatis, 14 de Dezembro de 1682; ASTo, Corte, MPRI, Storia della real casa di Savoia, Cat. 3, m. 20, "Reflexions sur le marriage de S.A.R.", sobre o insucesso do projecto e sobre a culpa em parte atribuída a Cadaval. Parece que o próprio Cadaval havia sido um potencial candidato à mão da infanta (DE SONNAZ, 1910, p. 146).

3 Sobre a logística da viagem, veja-se, por exemplo, ASTo, Corte, MPRE, Negoziazioni col Portogallo, m. 1, "Memoire pour la départ de S.A.R.".

${ }^{4}$ ASTo, Corte, MPRE, Lettere Ministri, Portogallo, m. 2, fasc. 1, 137, De la Torre a Gubernatis, 2 de Novembro de 1682. Sobre tal indisposição durante o Verão, consulte-se, e.g., ASTo, Corte, MPRE, Negoziazioni col Portogallo, m. 1, "Journal de la maladie de S.A.R.". 
um mal-estar simulado, concebido por um jovem duque teimoso para escapar ao desejo da mãe para que deixasse os estados saboianos? Ou o episódio tinha sido arquitectado pela própria mãe, Maria Joana Baptista (1644-1724), para contrariar a forte oposição interna às núpcias, oposição agravada pela perspectiva de um príncipe reinante partir para outro país e pela influência da França sobre a regente?

\section{A historiografia sobre o casamento}

Atrás destas interrogações, há uma série de questões mais profundas e centrais a ter em conta neste estudo: questões sobre a natureza do governo da regência como fenómeno histórico, com a suas peculiares dinâmicas sociais e políticas; sobre as relações entre o ducado de Sabóia e Portugal e as potenciais insídias de uma união dinástica, no âmbito da qual cada Estado devia responder às suas próprias pressões internas; e, mais global, sobre a verdadeira natureza do ducado, na Europa da primeira Idade Moderna. Um relatório sobre Portugal, quase contemporâneo, redigido pelo filósofo de Cambridge John Colbatch e editado em Londres em 1700, oferece uma interpretação do insucesso matrimonial que para os historiadores do Piemonte e Sabóia toca estes pontos-chave. Segundo Colbatch, o casamento gozava do apoio, quer de Maria Joana Baptista, a chamada segunda Madame Real, regente dos domínios saboianos desde a morte de Carlos Manuel II, ocorrida em 1675, quer da sua irmã, a rainha D. Maria Francisca Isabel de Portugal (1646-1683), mãe da infanta, nascida do seu segundo marido, o regente português D. Pedro (1648-1706). Graças a essas núpcias, Madame Real teria podido prolongar a sua regência, afastando o duque da Sabóia, pois quando Vítor Amadeu atingisse a maioridade, completando catorze anos em 1680, ela continuaria a governar em seu nome. Muito possivelmente, como alguns têm acentuado, Madame Real teria podido prolongar a sua regência por um tempo indefinido ${ }^{5}$. Por outro lado, Col-

\footnotetext{
5 Sobre este ponto de vista de fonte quase contemporânea, cf. por exemplo POMPONNE, 1860, pp. 86-87. Na historiografia sobre Maria Joana Baptista a ideia persistiu longamente: ver, e.g. CARUTTI, 1875-80, III, p. 81, e CONTESSA, 1915, p. 123.
} 
batch sugeria que o casamento atraía a rainha portuguesa, visto que, do ponto de vista de Maria Francisca Isabel, ele ter-lhe-ia permitido manter o domínio sobre a única filha, impedindo-a de desposar um príncipe "estrangeiro" e estranho à família. Maria Francisca Isabel não podia ter outros filhos e Isabel Luísa, seja dito, tinha sido nomeada herdeira presuntiva de Portugal nas cortes reunidas a 27 de Janeiro de 1674, pois o rei legalmente reconhecido, Afonso VI (1643-1683), primeiro marido de Maria Francisca Isabel, tinha sido declarado inábil para governar. As disposições do reino, que permitiam a sucessão quer masculina, quer feminina, apoiavam a infanta.

Para além disso, como notam outras fontes, uma união com o Estado de Sabóia oferecia ulteriores vantagens potenciais aos Portugueses, "que se tornariam importantes em Itália como os Espanhóis e capazes de fazer mais barulho na Europa do que fazem agora" ${ }^{6}$. O assunto foi desenvolvido mais explicitamente nas instruções dadas por Vítor Amadeu II ao marquês de Dronero em 1680, as quais merecem ser reproduzidas por extenso. Com o fim de elogiar os principais membros do reino e do conselho de estado português, Dronero deveria argumentar que

"Um Rei de Portugal, Senhor da Sabóia e do Piemonte será o árbitro da paz e da guerra. A Itália considerá-lo-á como o seu bastião, a França como o terror e ruína dos Castelhanos, se se declarar contra eles, e os próprios Castelhanos como o único refúgio contra o desmesurado poder dos seus vizinhos. Será então que o Império Português, reunindo os mares do Oriente e do Ocidente ao Mediterrâneo, poderá vangloriar-se de não ter outras fronteiras senão as do Mundo."7

Uma união com Sabóia teria também aberto a possibilidade de uma unificação da Península Ibérica sob um único príncipe. Dada a fragilidade do trono espanhol durante o reinado de Carlos II (1661-1700), o duque de

\footnotetext{
6 ASTo, Corte, MPRI, Storia della real casa di Savoia, Cat. 3, m.20, "Reflexions..."; CONTESSA, 1915, p. 125. Ver também ASTo, Corte, MPRI, Matrimoni m. 32, fasc. 14, "Premiere écriture sur la proposition du mariage de Portugal pour S.A.R.”, 1679.

7 ASTo, Corte, MPRI, Matrimoni, m. 32, fasc. 44, Instruções a Dronero, 1680.
} 
Sabóia poderia aparecer como pretendente à coroa ${ }^{8}$. Se as aspirações se tivessem concretizado, com Vítor Amadeu II consorte da infanta Isabel Luísa, os papéis da Espanha e Portugal pós-1580, ter-se-iam invertido dramaticamente, agora com vantagem para Portugal.

Todavia, Colbatch observava também que o casamento parecia ter tido pouco apoio em Sabóia, sobretudo porque parecia submeter-se à excessiva influência francesa sobre Madame Real. Luís XIV (1638-1715) tinha intenção de tirar partido das núpcias - argumentava Colbatch - para obter uma via de penetração em Itália, a fim de assegurar os interesses franceses em caso de guerra com a Espanha, para a qual Milão era ainda um domínio-chave na sua monarquia compósita. Dever-se-á acrescentar que durante as primeiras fases do projecto matrimonial, Franceses e Espanhóis estavam em conflito, resolvido pelo Tratado de Nimega, de Setembro de 16789. Como assinalou Colbatch, a presença dos exércitos franceses nas fronteiras da Sabóia (prontos a ameaçar Milão), só aumentou os receios no ducado. Na realidade, Luís XIV tinha até oferecido tropas ao governo de regência para conter a instabilidade que, desde 1680 e devido às taxas sobre o sal, aumentava no território piemontês de Mondovi. Além disso, como veremos, os Franceses não só continuaram a ocupar a fortaleza piemontesa de Pinerolo, como também, em Setembro de 1681, obtiveram o controlo da cidadela de Casale, em Monferrato, aumentando ainda mais a impressão da sua excessiva influência sobre Sabóia. Tal convergência de distúrbios regionais no seio dos estados saboianos com a perspectiva da partida do jovem duque para Portugal e o espectro da França, provocou a oposição aberta de um grupo de cortesãos de Vítor Amadeu II. Encabeçada por Emílio San Martino de Parella (embora não mencionado por Colbatch), a facção procurou persuadiu o duque a romper o noivado preparado pela mãe. Ao mesmo tempo, foi mobilizada a oposição popular diante do palácio ducal de Turim. Madame Real sobreviveu à tentativa de golpe de estado cortesão, que pretendia também afastá-la do poder, mas a viva hostilidade interna ao

\footnotetext{
8 CONTESSA, 1915, p. 127.

${ }^{9}$ A estratégia francesa de ameaçar Milão via Sabóia pode ver-se nas instruções ao marquês de Villars na qualidade de embaixador extraordinário, em Abril de 1676, e nas da missão em Setembro de D'Estrées em Setembro de 1677. DE BEAUCAIRE, 1898, I, pp. 81-90, 93-100.
} 
projecto convenceu-a do facto de que, se seu filho tivesse casado com a prima portuguesa e tivesse partido para Lisboa, a sua própria sobrevivência dependeria cada mais da França. Foi então que, no seu interesse, como concluiu Colbatch, ela escolheu desistir do casamento, mesmo que isso, como era previsível, a conduzisse ao fim da regência ${ }^{10}$.

Embora alguns elementos sejam duvidosos e o autor tenha dado escassa atenção às indecisões expressas também em Portugal sobre o enlace entre o duque de Sabóia e a infanta portuguesa, o relato de Colbatch da ruptura do contrato é apreciável e concorda amplamente com outras fontes coevas. Colhemos na sua crónica algumas etapas fundamentais da história saboiana, apesar da insistência na insaciável vontade de Maria Joana Baptista em controlar o ducado. Colbatch parece ter compreendido os dilemas das regências: quando havia que abandonar o poder, em que circunstâncias devia ser feita a transição e, sem dúvida, os potenciais problemas internos que lhes eram inerentes. As regentes, pela sua própria natureza, eram definidas como mães: guardiãs dos filhos, que deveriam substitui-las quando atingissem a maioridade. Assim, os governos de regência tinham quase sempre aparência de fracasso. Partindo do princípio que os príncipes sobreviviam, o poder na corte estava vinculado à troca das regentes pelos jovens governantes, segundo uma dinâmica que continha implícita a possibilidade de criar instabilidade política ao seio das elites e de outros membros das casas reinantes ${ }^{11}$. Tudo isto se vê muito claramente no caso das rainhas-mães de França da primeira metade de Seiscentos, Maria de Médicis (1575-1642) e Ana de Áustria (1601-1666). Maria de Médicis teve de defrontar-se com o filho, Luís XIII, quando este atingia a maioridade, e, em 1617, foi forçada a um exílio temporário em Blois. A mãe de Luís XIV, Ana de Áustria, por sua vez, teve que enfrentar uma conjura de parlementaires e aristocratas que se opunham ao seu ministro/favorito Mazarino, durante as violentas desordens que marcaram os anos da Fronda (1648-1652). Na própria Casa de Sabóia, a primeira Madame Real, Maria Cristina

\footnotetext{
10 COLBATCH, 1700 , pp. 129-140. Para uma crítica a esta interpretação, acentuando a culpa de Cadaval pelo insucesso do projecto, ver CARUTTI, 1863, p. 69.

11 Consulte-se SYMCOX, 2002, p. 199.
} 
(1606-1663), viu-se envolvida na guerra civil do Piemonte (1638-1642), em parte provocada pela rivalidade com os seus cunhados Sabóias, quando foi regente em nome do único filho que lhe restou, Carlos Manuel $\mathrm{II}^{12}$.

Mais em geral, e porventura mais importante, Colbatch salientava o carácter ambíguo da Sabóia enquanto estado independente da Itália setentrional, situado geoestratégica, política e até dinasticamente entre as superpotências da França e a Espanha. Este tema, em particular, constituiu uma ideia fixa dos historiadores saboianos, talvez de modo ainda mais evidente para os que escreveram nos alvores da unificação italiana. Uma das figuras de maior relevo da escola historiográfica oitocentista, Domenico Carutti, tinha poucas dúvidas sobre o grau da influência francesa ou sobre a fraqueza da regência, ao tempo do projecto matrimonial aqui estudado, apesar de se afastar de algumas das mais duras críticas à política de Maria Joana Baptista, no seu clássico estudo sobre o reinado de Vítor Amadeu II. Foi mais cáustico na sua análise da diplomacia saboiana, iniciando a sua narrativa do projecto com as seguintes declarações: "Em 1678, tiveram início os graves erros de Madame Real e os abusos de Luís XIV"13. Outros historiadores, italianos e não só, foram muito pouco indulgentes com Maria Joana Baptista, reiterando a sua imagem de marioneta francesa que, não obstante, procurou em vão manter o poder como regente, "dominada pela ambição conjugada com a fraqueza”, nas palavras de Gaudenzio Claretta $^{14}$. Uma outra importante história diplomática de finais do século XIX, redigida por Camille Rousset, historiador oficial do Ministério da Guerra francês, apresenta um esboço de Madame Real. A obra retrata-a como uma governante fraca, cuja sujeição à influência francesa se tornou ainda mais evidente quando eclodiram as revoltas de Mondovi e quando, em Novembro de 1682, assinou um tratado de aliança com a França que permitia a esta última manter tropas de guarnições no ducado. Segundo Carutti,

\footnotetext{
12 Embora Carutti sugira que a regência de Madame Real terminou em 1684, não tanto como a explosão de problemas internos, mas como um gemido de impotência: CARUTTI, 1863, pp. $90-1$.

13 CARUTTI, 1863, cap. III e IV; CARUTTI, 1875-80, III, p. 80. Para algumas considerações sobre o legado historiográfico da unificação, cf. ORESKO, 2004, p. 16. Para uma outra recente interpretação, veja-se a entrada de MERLOTTI, A. no Dizionario Biografico degli Italiani.

14 CLARETTA, 1865, p. 119. Ver também p. 125.
} 
as cláusulas do acordo "esclareciam que a França considerava o Piemonte como província sua e o governo local como sua lugar-tenência” 15 .

Se a suposta fraqueza saboiana durante a regência é uma face da moeda de uma velha corrente historiográfica, o seu reverso é que o ducado, vitalizado pela enérgica autoridade de Vítor Amadeu II, se tornou um bastião da independência da península itálica contra o jugo estrangeiro. Carutti, por seu lado, evidenciou profundas e crescentes divergências entre Madame Real e o jovem Vítor Amadeu sobre o projecto nupcial, reconhecíveis, por exemplo, no facto de eles terem enviado ao marquês de Dronero instruções diferentes e separadas para a sua missão em Lisboa, em 1680. Talvez nisso estivesse implícita a percepção não apenas das dificuldades do governo de regência em si mesma, do tiquetaque da bomba-relógio de um príncipe a atingir a maioridade, mas também da forte personalidade manifestada por Vítor Amadeu contra a mãe dominada pela França, anunciando o carácter voluntarioso do príncipe, que emergiria no palco da política europeia como um maduro governante da Sabóia ${ }^{16}$. Por sua parte, Carlo Contessa argumentou que a tentativa de golpe marquês de Parella para arrancar o poder a Maria Joana Baptista, respondia à ameaça da influência francesa inerente àquele casamento. Parella não podia admitir a submissão ao domínio estrangeiro. Em contraste, a conspiração teria sido um acto de independência em nome da Sabóia, ajudado por Veneza e por Milão (controlada pelos Habsburgos), embora o crescente envolvimento destes últimos territórios pudesse ameaçar as aspirações de independência face às grandes potências. Nas suas observações conclusivas, Contessa interpretava claramente a intentona de Parella à luz do papel da Sabóia numa activa autonomia do poder italiano dos finais de Seiscentos e inícios do século XVIII, culminando no envolvimento de Vítor Amadeu II na Guerra da Sucessão Espanhola (1701-14). Esta interpretação foi duradoura. Num estudo mais recente sobre as guerras do sal de Mondovi, Giorgio Lombardi caracterizou os adeptos do casamento como

15 ROUSSET, 1861-3, III, p. 41; CARUTTI, 1863, p. 53. Veja-se também DE BEAUCAIRE, 1898, pp. $110-16$.

16 CARUTTI, 1863, p. 62. 
"filo-franceses", definindo por sua vez como "dinásticos" os que queriam que Vítor Amadeu ficasse na Sabóia a salvaguardar a sua independência, articulando assim as revoltas locais de Mondovi com a política dinástico-internacional e geoestratégica dos Sabóias ${ }^{17}$.

Estas robustas tradições historiográficas moldaram a forma como vemos o Piemonte e Sabóia no contexto europeu, com o casamento português lido como importante episódio a confirmar essa interpretação. O projecto e o seu fracasso parecem proceder de duas visões contrapostas, a da Itália moderna subjugada ao domínio estrangeiro e a que via na Sabóia a defensora da liberdade italiana ou, pelo menos, potência capaz da independência, sobretudo porque Vítor Amadeu II desempenhou acção de relevo nas guerras que sacudiram a Europa entre o fim do século XVII e o início do século XVIII e no processo de reconhecimento a nível internacional da Coroa régia da Casa de Sabóia (o reino da Sicília, depois suplantado pelo da Sardenha). Será também possível ter do projecto matrimonial uma visão mais matizada, que congregue estas visões historiográficas contraditórias, mas que também demonstre uma maior percepção das dinâmicas dinásticas tão importantes para a Casa de Sabóia no decurso da Idade Moderna? O falecido Robert Oresko, que tanto contribuiu para aprofundar o nosso conhecimento sobre a política cultural e dinástica dos Sabóias, num texto sobre a poder régio feminino na Europa moderna, apresentou um perfil diferente de Madame Real, uma antevisão do seu inacabado estudo de fundo sobre Maria Joana Baptista. No seu sugestivo contributo, Oresko reconhecia, é certo, o envolvimento da França no projecto matrimonial. Mas apresentava Madame Real com mais simpatia, interpretando a sua regência como um todo, até ao momento em que se retirou a favor do filho, em 1684, em termos de profunda lealdade ao destino da Casa de Sabóia. Além disso, sublinhou a sua aptidão, pelo menos na primeira metade da sua regência, para concretizar estratégias diplomáticas autónomas de Luís XIV. Outro importante historiador anglo-americano, Geoffrey Symcox, no seu capítulo sobre o período da regência

17 CONTESSA, 1936, pp. 80-142; LOMBARDI, 1986, p. 115. Ver relato duplo dos acontecimentos pertencentes à mesma tradição historiográfica em FERRERO LA MARMORA, 1862, cap. VII; FERRERO LA MARMORA, 1863, cap. III. 
publicado na seminal História de Turim Einaudi ${ }^{18}$, chegou a conclusões semelhantes sobre as capacidades políticas de Maria Joana Baptista.

\section{2. "Notre grand dessein": o casamento como um acordo familiar.}

Nesta óptica, podemos realçar a importância das dinâmicas do pensamento dinástico, alicerçando-o na ideia de que Maria Joana Baptista e a sua irmã se norteavam em grande medida pela lealdade à Casa de Sabóia, mais do que por uma estreita noção de ambição pessoal ou servilismo à França. Uma perspectiva distinta do projecto matrimonial como caso de estudo no âmbito da política dinástica saboiana permite-nos, portanto, rever a nossa compreensão dos Sabóias nos seus estados italianos e europeus. No âmago do plano nupcial estava a relação funcional entre as duas irmãs Sabóia-Nemours. Como Colbatch argumentou, Madame Real e Maria Francisca Isabel queriam manter os seus dois estados na família. Ironicamente o impulso terá vindo em parte da candidatura à mão da infanta portuguesa de Maximiliano Manuel de Baviera (1662-1726), o filho de Henriqueta Adelaide (1636-1676), irmã de Carlos Manuel II e, assim, ele próprio ligado à Casa de Sabóia. A oportunidade de um casamento ainda mais próximo na família, envolvendo o próprio duque de Sabóia, teria parecido demasiado boa a Maria Joana Baptista para que a deixasse escapar e configurava-se como uma boa solução também para a rainha portuguesa que desejava casar a filha ${ }^{19}$. O tom de intimidade entre as irmãs colhe-se tanto na correspondência entre as duas, como no seu claro envolvimento no projecto, e acrescente-se que, por várias vezes, foi Maria Francisca Isabel a assumir a prossecução do plano, enquanto a irmã, em Turim, exprimia algumas dúvidas $^{20}$. O casamento era, como escrevia Maria Francisca nas suas cartas à

18 ORESKO, 2004, pp. 28-34; SYMCOX, 2002, p. 199. Para a precoce interpretação de Symcox da regência e do casamento, veja-se a sua importante biografia de Vítor Amadeu: SYMCOX, 1983, cap. V.

19 ASTo, Corte, MPRI, Storia della real casa di Savoia, Cat. 3, m. 20, "Reflexions..."; CLARETTA, 1863, pp. 247-248.

${ }^{20}$ Por exemplo, ClareTTA, 1865, pp. 242-6. 
regente da Sabóia, "notre grand dessein" ("o nosso grande desígnio"), ou mais frequentemente "notre affaire" ou ainda "notre plus parfaite union", nas palavras de Maria Joana Baptista, embora escritas na missiva que marcou o fim das negociações 21 .

Na ambição de Maria Joana Baptista em assegurar um título régio e no manifesto entusiasmo de Maria Francisca Isabel por uma ligação aos Sabóias prevalecendo sobre outras dinastias, vemos a solução para o problema das duas irmãs em ajustar os casamentos dos filhos solteiros, assumindo as suas responsabilidades enquanto membros de um ramo secundário da Casa de Sabóia 22 . Tal interpretação ajusta-se ao comportamento típico dos segundogénitos face aos ramos principais das famílias. A linha dos Sabóia-Nemours tinha as suas origens no princípio do século XVI, quando o duque Carlos II de Sabóia (1486-1553) deixou como apanágio o condado de Genebra ao irmão mais novo Filipe (1490-1533), que mais tarde, em 1528, recebeu também o ducado de Nemours do seu sobrinho, Francisco I de França. A divisão dos títulos e dos territórios entre a Sabóia e a França teve importantes consequências sobre os Sabóia-Nemours, cujos interesses, previsivelmente, se cruzavam entre os dois Estados - Maria Joana Baptista e Maria Francisca Isabel, filhas de uma sobrinha de Henrique IV, Isabel de Bourbon-Vendôme (1614-64), tinham até crescido em França. A morte do pai delas, Carlos Amadeu de Sabóia-Nemours, num duelo em 1652, havia deixado a família numa posição precária: o único herdeiro varão ao título de duque de Sabóia-Nemours, Henrique de Sabóia, tinha-se tornado arcebispo de Reims em 1651, vindo a falecer sem herdeiros em 1659, apesar de casado em 1657. Mas já antes da morte de Henrique, a maioria das possessões da família, na Sabóia e na França, haviam passado para as mãos das duas irmãs, e, decerto, Maria Joana Baptista usufruiu de recursos pessoais enquanto duquesa de Sabóia que lhe

21 Cf., por exemplo, ASTo, Corte, MPRI, Lettere Principi Diversi, m. 82, Maria Francisca Isabel a Madame Real, 14 de Maio de 1679; ASTo, Corte, MPRE, Negoziazioni col Portogallo, m. 1, fasc.2, Madame Real a Maria Francisca Isabel, 22 de Dezembro de 1682.

${ }^{22}$ A infanta teve um amplo leque de pretendentes, desde de Conti, um príncipe francês de sangue real, a Jacques Sobieski, filho do rei da Polónia: FARGES, 1907, pp. 357-77. Para um elenco coevo dos vários possíveis cônjuges, ver ASTo, Corte, MPRI, Matrimoni m. 32, fasc. 18, "Alcune considerationi circa i Principi, che concorrono alla pretensione del matrimonio della Ser.ma Principessa di Portogallo", c.1678. 
permitiram promover um ambiente de corte culturalmente vibrante, apesar desse património estar situado em França ${ }^{23}$.

Para as dinastias reinantes, os ramos secundários eram recursos de dupla face social e política. Podiam ser ameaças potenciais para o ramo principal das dinastias e o pontos focais da oposição aos príncipes reinantes, até porque os cadetes tanto podiam ter pretensões dinásticas ao trono como a distância suficiente para actuarem de forma autónoma. Como no caso dos Sabóia-Nemours, os segundogénitos podiam também dispor de recursos noutros estados, como propriedades, títulos, cargos, ou até direitos feudais, levantando questões sobre distintos deveres de lealdade. Por outro lado, o facto de os ramos secundários poderem ter interesses e responsabilidades noutros lugares podia criar divisões políticas entre cortes rivais e eles próprios podiam servir de solução para as dinastias principais no caso de fragilidade biológica. No século XVI, o membro principal do ramo Sabóia-Nemours, Jacques de Sabóia, duque de Nemours (1531-85), fez carreira, tanto na corte francesa, como na de Sabóia, evidenciando as ambiguidades dos príncipes cadetes que se moviam entre os dois estados e, no seu caso, a possibilidade que teve de talhar um Estado por sua conta. Contudo, como recentemente mostrou Matthew Vester, a sua estreita associação com o tronco principal da Casa de Sabóia pode ser entendida como uma coligação de interesses. Como observa Vester, Jacques de Sabóia não se considerava um actor isolado, mas um membro de um grupo familiar mais vasto que incorporava a dinastia de Sabóia ${ }^{24}$. Dentro desta estrutura dinástica de ramos secundários que se moviam em estratégias discretas permanecendo, em simultâneo, conscientes das responsabilidades que tinham perante os ramos principais das famílias, um casamento entre o filho do duque de Sabóia e a única filha da rainha de Portugal torna-se então perfeitamente compreensível. Como ramo da Casa de Sabóia, os Sabóia-Nemours estavam simplesmente a reentrar na linha dinástica principal, enriquecendo-a e

23 ORESKO, 2004, p. 17.

24 VESTER, 2008, p. 330. Para algumas considerações gerais sobre a família de Sabóia-Nemours, datadas de pouco antes do projecto matrimonial, ver GUICHENON, 1660, II, pp. 1049-76. Sobre os ramos secundários em Itália da primeira Idade Moderna, cf. SPAGNOLETTI, 2003, cap. IV. 
reforçando-lhe o poder, e não o faziam por menos: retomavam as históricas filiações genealógicas com a Coroa de Portugal.

\section{A sombra da França.}

Se o casamento pode ser entendido como acção dos Sabóia-Nemours, trabalhando em comum em prol da Casa principal, que dizer do significado político mais alargado do projecto? Podemos antes de mais avançar com a questão do envolvimento da França num plano que era observado de perto por toda a Europa. Em que grau isso influenciou a tradição historiográfica da predominância francesa no século XVII, que tanto modelou a nossa visão da Sabóia moderna? Durante as negociações matrimoniais, ambas as irmãs Sabóia-Nemours contaram, inegavelmente, com o apoio da França. Como vimos, elas eram princesas francesas de nascimento e os seus casamentos tinham sido em parte negociados pelo tio-avô, o cardeal de Estrées, um embaixador francês de primeiro plano, que tinha desempenhado missões diplomáticas em Roma e em Madrid. Além disso, ao regime francês foi atribuído um papel privilegiado no projecto matrimonial: tanto Madame Real como a irmã procuraram ocultar o projecto dos outros governos europeus, pelo menos até se encontrar suficientemente avançado para ser seguro. É que havia grupos com interesses rivais que aspiravam à mão da infanta, incluindo a Espanha e o maior rival da Sabóia na península itálica, a Toscana; a Espanha, em particular, tinha motivos para temer a união Sabóia-Portugal ${ }^{25}$. Mas os Franceses foram informados em primeiro lugar e as duas irmãs pretendiam claramente manter informados Luís XIV e seus ministros das suas intenções mais gerais, embora não descendo sempre a pormenores ${ }^{26}$. Foi esta a situação, decerto por

\footnotetext{
25 ASTo, Corte, Lettere Ministri Spagna, m. 33, 231, Gubernatis a Madame Real, 27 de Março de 1680.

26 Por exemplo, DÓRIA, 1944, pp. 316-317; ASTo, Corte, MPRE, Lettere Ministri Francia, m. 109, fasc. 1, 22-3, cópia da carta de Maria Francisca Isabel a Luís XIV, 14 de Dezembro de 1678; 25v, Madame Real a Luís XIV, fim de 1678; ASTo, Corte, MPRE, Negoziazioni col Portogallo, m. 1, fasc. 1, instruções a Gubernatis, 19 de Setembro de 1679. Vale a pena acrescentar que antes da candidatura de Vítor Amadeu II, Maria Francisca Isabel tinha recebido conselhos do
} 
vontade da Sabóia, durante o processo de negociações dos termos do casamento, ao longo de $1679^{27}$.

Em termos gerais, a França parece ter apoiado o projecto: no Outono de 1682, por exemplo, os Franceses disponibilizaram um navio para conduzir Vítor Amadeu II a Portugal, a fim de acelerar o processo ${ }^{28}$. Na perspectiva francesa, a ligação entre Sabóia e Portugal teria podido evitar o renovado perigo de uma união portuguesa com a Espanha, ou um casamento com um príncipe imperial - era, por isso, a segunda melhor opção depois da falhada tentativa de casar a infanta com um candidato francês ${ }^{29}$. Além disso, como o casamento português alinhava Sabóia com a França contra a Espanha, o ducado aumentava o seu valor para os interesses geo-estratégicos da França em Itália, que, ao longo do século XvII, se tinham mantido ao nível defensivo. Como disse o abade Scaglia, embaixador de Turim em Paris, em boa parte de 1679 "por parte dos franceses vemos claramente que a sua intenção não foi fazer aquisições em Itália, mas apenas manobras de diversões" 30 . Pelo menos até à guerra de 1628-1631, pela sucessão de Mântua e do Monferrato, ficou claro que o regime francês via o Norte de Itália, e a Sabóia em particular, como uma componente-chave de uma estratégia internacional para limitar o poder espanhol, aparentemente agressivo, colocando sob pressão a logística da monarquia compósita na Lombardia. O controle das fortalezas de Pinerolo e Casale tornou-se essencial para tal estratégia. A ocupação francesa de Pinerolo permaneceu depois do fim do conflito. Casale, cuja impor-

cardeal d'Estrées sobre as opções matrimoniais da filha. DÓRIA, 1944, p. 307. Mais em geral, consulte-se DE MANNEVILLE, 1931, se bem que nem sempre seja muito preciso.

27 Por exemplo: ASTo, Corte, MPRE, Lettere Ministri Francia, m. 109, fasc. 1, 179v-81v, Madame Real a Scaglia, 20 de Maio de 1679; 315-16, Madame Real a Scaglia, 16 de Setembro de 1679.

28 ASTo, Corte, MPRE, Lettere Ministri Portogallo, m. 2, fasc. 1, 131, De la Torre a Gubernatis, 21 de Setembro de 1682.

29 Sobre a oposição francesa a um casamento hispano-português cf., por exemplo, ASTo, Corte, MPRE, Lettere Ministri Portogallo, m. 3, fasc. 1, 10, Spinelli a Madame Real, 4 de Abril de 1678; COLBATCH, 1700, p. 131. Entre os pretendentes imperiais à mão da infanta contava-se o duque de Neuburg, pessoa demasiado próxima dos Habsburgos da Áustria para poder agradar à França. ASTo, Corte, MPRE, Lettere Ministri Portogallo, m. 2, fasc. 2, 142, Gubernatis a Maria Francisca Isabel, 22 de Janeiro de 1683.

30 ASTo, Corte, MPRE, Lettere Ministri Francia, m. 108, fasc. 2, 74, Scaglia a Madame Real, 9 de Junho de 1679. 
tância tinha sido comprovada durante a primeira metade de Seiscentos, estava para ser transferida da posse do duque de Mântua para a França, em virtude de um acordo secreto datado de 8 de Julho de 1681. Foi ocupada em Setembro por tropas que tinha atravessado o Piemonte (um acto que, por si só, parece confirmar a autoridade de Luís XIV sobre Madame Real).

Havia ainda outras evidentes vantagens para a França nas núpcias saboiano-portuguesas. Teriam impedido uma união entre os Habsburgos e os Braganças, enquanto eram reforçadas as relações diplomáticas com Turim, como parte da estratégia continuada de limitação do poder espanhol. Antes de concluir, todavia, que o projecto nupcial confirma a expansão da influência francesa no Norte de Itália, devemos recordar que não foi concebido em Paris, mas em Turim e em Lisboa. Não era a primeira escolha francesa, que, num primeiro momento, tinha avançado com a candidatura do príncipe de Conti. Nem devemos subvalorizar a ansiedade provocada pelo facto de tal união poder criar um bloco demasiado poderoso até mesmo para a França. Já vimos que os Sabóias tinham direitos potenciais ao trono espanhol, um factor que pode ter influenciado os Portugueses a favor da núpcias. De facto, já em 1676, os próprios Espanhóis tinham 'flirtado' com a ideia de uma possível união com os Sabóias, falando "com o mel na boca” da sua admiração por Madame Real e acrescentando o seu pesar pelo facto de ela não ter uma filha que pudesse casar com Carlos $\mathrm{II}^{31}$. A possibilidade de uma sucessão saboiana na monarquia espanhola, todavia, provocava grande impressão em França, como notou o abade Scaglia durante uma conversa com o marquês de Pomponne, o secretário de estado francês dos negócios estrangeiros:

"Uma só consideração o mantinha perplexo; e é, que sendo S.A.R. [Vítor Amadeu II] chamado à sucessão da Coroa de Espanha, e estando esta suspensa por um fio, podia acontecer que em breve tempo se assistisse à união não só de Castela a Portugal, como do Ducado de Milão ao

31 ASTo, Corte, MPRE, Lettere Ministri Spagna, m. 33, Gubernatis a Madame Real, 23 de Junho de 1676. 
Estado do Piemonte e ao Ducado da Sabóia; e que, por isso, sendo um negócio revelantíssimo, que altera todo o governo da Europa, convinha tomar medidas adequadas com a França."32

Apesar da tradicional ideia do poder franco-espanhol na Itália moderna, a França não conseguia controlar totalmente a Sabóia. Os Franceses continuaram a delinear a sua política em termos defensivos com o fim, por exemplo, de proteger os corredores militares no interior do ducado para conter o poderio espanhol. Como tal, a sua estratégia em relação a Sabóia teve de ser conduzida sob a aparência de uma cooperação. Ainda mais importante, a Casa de Sabóia reinante exerceu o poder através dos seus vínculos dinásticos, possuidores de um dinamismo inerente e potencialmente incontrolável. O projecto matrimonial Sabóia-Bragança não foi instigado pelo regime francês e acarretava consequências que não teriam sido bem-vindas: o casamento apresentava uma igual mistura de incertezas e oportunidades. De resto, a ambiguidade de fundo dos Sabóias tinha sido um tema recorrente nas relações franco-piemontesas desde inícios do século. 33

\section{A retórica do espírito dinástico dos Sabóias}

Se é possível descrever o envolvimento francês no projecto em termos de uma longa e ambígua relação com a Sabóia, podemos também caracterizar dessa forma o casamento, enraizando-o na retórica dinástica da Casa de Sabóia. O casamento, em suma, era uma réplica da íntima afinidade com Portugal - como este volume demonstra amplamente -, e a afirmação da autoproclamada identidade régia dos Sabóias. Durante as negociações, o cenário genealógico e histórico do projecto integrou a retórica saboiana.

32 ASTo, Corte, MPRE, Lettere Ministri Francia, m. 108, fasc. 2, 17, Scaglia a Madame Real, 11 de Fevereiro de 1679. Veja-se também ASTo, Corte, MPRI, Lettere Principi Diversi, m. 82, Maria Francisca Isabel a Madame Real, 14 de Maio de 1679; ASTo, Corte, MPRI, Storia della real casa di Savoia, cat. 3, m. 20, "Reflexions...".

33 OSBORNE, 2002, cap. 6. 
Tal se depreende das instruções de Vítor Amadeu II a Dronero, enviado a Lisboa depois da ratificação do contrato nupcial, e de um documento apresentado ao Conselho português, onde se afirma com clareza que "les alliances des Portugais avec Savoye sont aussi anciennes que leur Monarchie" ("as alianças dos Portugueses com a Sabóia são tão antigas como a sua Monarquia”). Não era só a Sabóia a utilizar esta ubíqua retórica quando se tornava politicamente oportuna, pois os Portugueses gostavam também de apelar à antiguidade das suas ligações, como testemunha uma carta de D. Pedro ao Papa Inocêncio XI ${ }^{34}$. E encontra-se o mesmo no preâmbulo do próprio tratado matrimonial 35 .

Todavia, talvez tal linguagem de intimidade familiar de longa data fosse mais importante para a Sabóia, por causa das aspirações régias da Casa ducal, que do casamento, no plano da reputação dinástica, era quem tinha mais a ganhar. Os vínculos com Portugal, juntamente com as ligações dos Sabóias às famílias imperiais e outras dinastias régias, significavam que a Casa de Sabóia achava que merecia uma posição de igualdade entre as dinastias monárquicas da Europa. Um relatório veneziano, escrito um século antes, em 1573, pelo embaixador da república em Turim, Girolamo Lippomano, revela a intimidade e a consciência de paridade de que, sem dúvida alguma, gozava o duque de Sabóia:

"[C]om a Alemanha [o duque Manuel Felisberto] é considerado alemão, sendo da Casa da Saxónia; com os Portugueses, português, por ter sido sua mãe filha do rei de Portugal, Manuel, irmã da mãe do rei de Espanha; pelo mesmo parentesco e por ter estado tanto tempo em Espanha, e por lhe terem sido dados tantos cargos,... pode dizer-se também espanhol. Os Franceses crêem o mesmo, tanto por parentesco antigo, como pelo renovado com a mulher que tem."36

\footnotetext{
34 ASTo, Corte, MPRI, Matrimoni, m. 32, fasc. 44, "Proposition au conseil de Portugal sur le mariage de l'Infante avec S.A.R. Victor Amé, 1679”; fasc. 23, Dom Pedro ao Papa Innocenzo XI, 13 de Setembro de 1679. Veja-se também ASTo, Corte, MPRE, Lettere Principi Forestieri, m. 87, Dom Pedro a Vítor Amadeu II, 16 de Junho de 1681.

35 CLARETTA, 1863, p. 255.

36 ALBERI, II, pp. 203-204.
} 
Para a Sabóia, a união com Portugal através de Vítor Amadeu II, um século depois do relatório de Lippomano, era a confirmação do que a sua Casa pensava de si própria, isto é, que era intrinsecamente real.

Por outro lado, longe de enfrentar as negociações matrimoniais com um sentimento de inferioridade, a Casa de Sabóia achava que podia oferecer vantagens concretas a Portugal, reiterando um forte sentido de autoestima dinástica. O abade Giacomo Spinelli, enviado a Lisboa para negociar os termos exactos do contracto nupcial, fez notar ao padre de Ville, o jesuíta confessor da rainha Maria Francisca Isabel, os benefícios do casamento português: "Expus-lhes as qualidades e as prerrogativas da Casa de Sabóia, a vastidão dos seus domínios, a opulência dos seus estados, as inevitáveis consequências da sua união com Portugal”37. Dada o apreço que a Casa de Sabóia tinha pelo seu alto valor, não admira que na altura em que estavam a desenrolar-se as negociações matrimoniais, os embaixadores saboianos continuassem a procurar, por toda a Europa, alcançar o tratamento real. A reivindicação da natureza régia da família era um procedimento diplomático oficial que recuava à declaração pública do avô de Vítor Amadeu II, Vítor Amadeu I (1587-1637), em Dezembro de 1632. O processo de conquista do reconhecimento internacional da condição régia foi um tema-chave da política diplomático-cultural de Sabóia, expressa ao mais alto grau no constante esforço dos embaixadores turinenses para gozarem de dignidade real nas suas missões europeias ${ }^{38}$. Continuou a ser um elemento central da diplomacia da regente Maria Joana Baptista e era ainda matéria de contencioso com os principais rivais italianos dos Sabóias, a república de Veneza e o grão-ducado da Toscana. Isto é patente nos esforços para obter tal reconhecimento na corte de Carlos II em Inglaterra e nos problemas que se criaram quando parecia que o soberano o tinha concedido. A questão dominou as relações anglo-saboianas durante o período das negociações matrimoniais; de facto, veio

37 ASTo, Corte, MPRE, Lettere Ministri Portogallo, m. 3, fasc.1, 19, Spinelli a Madame Real, 27 de Junho de 1678; ASTo, Corte, MPRI, Storia della real casa di Savoia, cat. 3, m. 20, "Reflexions...". Para as instruções de Spinelli, veja-se ASTo, Corte, MPRI, Matrimoni, m. 32, fasc.

38 Mais em geral, veja-se ORESKO, 1997. O esforço saboiano para a obtenção do estatuto régio pode ser datado da década de 1580. OSBORNE, 2007, pp. 18-19. 
a associar-se directamente a esse projecto, pois alegava-se que uma união com Portugal faria, enfim, justiça às credenciais régias saboianas ${ }^{39}$. Nem se tratou apenas de uma matéria restrita a Londres, porque ao longo da segunda metade do século XVII e durante as negociações matrimoniais, esforços análogos para conseguir o reconhecimento régio foram feitos noutras cortes europeias, incluindo as de Lisboa, Paris e Madrid ${ }^{40}$.

O casamento português apresentava numerosas vantagens políticas para uma dinastia determinada a assegurar o reconhecimento internacional da sua grandeza. Oferecia também significativas oportunidades económicas. Desde os inícios do século XVII, os duques de Sabóia tinham consciência da sua relativa fraqueza económica, em parte porque os estados saboianos careciam da logística necessária para impor uma forte presença marítima. Em 1627, por exemplo, Alessandro Scaglia, embaixador de Carlos Manuel I em Londres, tinha tentado fazer de Nice-Villefranche um porto economicamente activo para os mercadores ingleses, segundo uma estratégia mais vasta que deveria alargar-se a mercadores franceses e holandeses ${ }^{41}$. Todavia, da iniciativa pouco ou nada resultou e a fraqueza marítima da Sabóia acentuou-se no decurso de Setecentos, como se tornou evidente no período dos conflitos europeus, quando o poder estava cada vez mais vinculado à capacidades coloniais ou mercantis. Demonstraram-no não só a expansão

39 Cf, por exemplo, ASTo, Corte, MPRE, Lettere Ministri Inghilterra, m. 6 e m. 7; TNA SP 92/25, Madame Real a Carlos II, 24 de Maio de 1681; Madame Real a Jenkins, 24 de Maio de 1681; Madame Real a Jenkins, 1 de Novembro de 1681; Vítor Amadeu II a Carlos II, 1 de Novembro de 1681. Vejam-se também as cartas de Soames a Jenkins de 12 de Julho de 1681 e de 23 de Novembro de 1681. Sobre as respostas a estas missivas, cf. TNA PRO SP 104/188, Jenkins a Soames, 25 de Julho de 1681. Para um relato mais amplo, embora nem sempre muito acurado, ver o apanhado coevo do episódio, escrito por um ex-servidor de Carlos II, em LETI, 1684, V, pp. 459-519.

40 Cf., e.g., ClARETTA, 1865, pp. 231-238; ASTo, Corte, MPRE, Lettere Ministri Francia, França, m. 108, fasc. 2, 74, Scaglia a Madame Real, 9 de Junho de 1679; ASTo, Corte, MPRE, Lettere Ministri Francia, m. 109, fasc. 1, 125-131v, Madame Real a Scaglia, 25 de Março de 1679; ASTo, Corte, MPRE, Lettere Ministri Spagna, m. 33, c. 15, Gubernatis a Madame Real, 23 de Junho de 1676, que inclui "Mottivi del Conte e Senatore De Gubnatoris per i trattamenti reggii nella Corte Cattolica a'favore di S.A.R. di Savoia suo sig.re”; 156, Gubernatis a Madame Real, 4 de Setembro de 1678. Para a regente o tratamento real era "uma particularidade assaz essencial”. ASTo, Corte, MPRE, Lettere Ministri Spagna, m. 34, c. 193v, Madame Real a Gubernatis, Outono de 1678.

41 Por exemplo, em TNA SP 92/13/25-7v, instruções a Alessandro Scaglia, 26 de Março de 1627; ASTo, Corte, MPRE, Lettere Ministri Inghilterra, m. 4, 50, Scaglia a Carlos Manuel I, 7 de Novembro de 1627. 
espanhola e portuguesa, como também a emergência e a rivalidade da Holanda, Inglaterra e França. Dada a disparidade económica entre a Sabóia e os outros grandes Estados europeus, o casamento português oferecia imensas potencialidades ao primeiro, pois Portugal situava-se num plano muito superior enquanto potência comercial de nível mundial. Para o ducado de Sabóia, as núpcias teriam garantido a oportunidade de estabelecer em Nice-Villefranche uma escala comercial, com a faculdade de um maior intercâmbio entre os dois Estados, de negócios e mercadorias, até mesmo de um comércio directo (embora cautelosamente controlado durante as longas negociações) entre o Brasil e os domínios de Sabóia, sem ter de passar primeiro por Portugal e pagar as tarifas aduaneiras ${ }^{42}$.

\section{Uma monarquia compósita?}

Enquadrámos, portanto, o projecto matrimonial no contexto de princípios dinásticos longamente amadurecidos e acoplado a questões, também arraigadas, de natureza geoestratégica e económica. Neste cenário vimos ainda como o projecto modifica a noção de domínio francês sobre a Sabóia. Todavia, não devemos descurar os problemas inerentes ao processo de negociação do casamento, sobre os quais versará esta última parte do estudo. As irmãs Sabóia-Nemours decerto desejavam uma solução "em família" para as núpcias dos seus filhos, mas isso levou-as a enfrentar consideráveis problemas internos nos seus Estrados ${ }^{43}$. Afinal de contas, nenhuma das delas estava em posição de poder inatacável, Maria Joana Baptista enquanto regente, e Maria Francisca Isabel como rainha cujas primeiras núpcias com o legítimo soberano, Afonso VI, tinham sido anuladas. Ainda mais: em ambos os estados havia um só herdeiro e, quer para a Sabóia, quer para

\footnotetext{
42 CLARETTA, 1865, p. 146; ASTo, , Corte, MPRI, Storia della real casa di Savoia, Cat. 20, m. 3, "Reflexions...". Para um relatório pormenorizado dos aspectos económicos do casamento e das suas várias complicações, cf. CONTESSA, 1915, pp. 123-179. Os termos exactos dos direitos comerciais saboianos foram matéria de longas negociações. Ver, por exemplo, ASTo, Corte, MPRE, Lettere Ministri Portogallo, m. 2, fasc. 2, correspondência de Gubernatis.

43 Cf., por exemplo, ASTo, Corte, MPRI, Lettere Principi Diversi m. 82, Maria Francisca Isabel a Madame Real, 27 de Novembro de 1682.
} 
Portugal (talvez mais para este), a questão de assegurar a sucessão era premente. Esta profunda preocupação em assegurar os tronos saboiano e português, obedece em aspectos importantes às dinâmicas - e problemas - de uma monarquia compósita, enquanto tipo de uma configuração política da modernidade. O assunto pode parecer paradoxal, considerando o que fora a história recente de Portugal. A integração do reino na carteira territorial espanhola em 1580 tinha acarretado consequências negativas para o país, pois se os Espanhóis a consideraram legitimada pelos interesses dinásticos de Filipe II, os Portugueses rapidamente perceberam que eram a parte prejudicada do acordo. Com um rei ausente, o reino tonara-se, de facto, o sócio minoritário da Espanha ${ }^{44}$.

Assim, os Portugueses não iriam repetir o erro com o casamento saboiano, mas este podia constituir um sério perigo para a Sabóia, não obstante, como vimos, as declarações retóricas da Casa de Sabóia sobre a sua intrínseca majestade e paridade com a dinastia portuguesa. A ameaça que constituía tal ligação foi decerto sentida em toda a Europa. Nas instruções dadas para a missão em Turim do embaixador francês, o abade d'Estrées, em Março de 1679, observava-se que "este assunto será capaz de enfrentar algumas dificuldades no Piemonte, pelo embaraço que os povos poderão sentir de se ver privados do seu príncipe, e de trocar um duque de Sabóia, que sempre terão entre si, por um rei de Portugal que jamais verão" 45 . A mesma questão emergiu num diálogo que em Agosto daquele ano Gubernatis e um membro do Consejo de Estado espanhol, o marquês de Astorga, mantiveram em Madrid. Cínico, Astorga perguntou como é que "os piemonteses deixavam sair o seu Príncipe natural dos seus próprios Estados". Gubernatis replicou que, "quando tal acontecesse, fariam como fizeram os súbditos de Filipe o Belo, quando se casou com a herdeira da Espanha, filha de Fernando o Católico". A contrarréplica de Astorga reiterou um dos problemas da união dinástica, e talvez de uma monarquia compósita, implícitos no projecto matrimonial saboiano: "Os Portugueses gostariam de

${ }^{44}$ Para um quadro geral da união com a Espanha, veja-se ELLIOTT, 1991. Sobre as dinâmicas das monarquias compósitas é de referir o clássico artigo do mesmo autor: ELLIOTT, 1992, pp. 48-71.

45 DE BEAUCAIRE, 1898, pp. 108-9. 
um Português natural para seu Rei, e esta foi a razão principal pela qual os Portugueses sempre abominaram o domínio dos Reis de Castela" 46.

A relação estabelecida por Guberantis entre o casamento saboiano-português com a união de 1496 entre Filipe o Belo (1478-1506) e Joana de Castela (1479-1555) é interessante e significativa, assim como a resposta de Astorga. Aquele consórcio tinha ligado os Países Baixos borgonheses com Castela e Aragão, criando um Estado compósito ainda mais poderoso, que fixaria os parâmetros fundamentais da monarquia espanhola nos séculos XVI e XVII. Contudo, esta evocação de uma união dinástica muito bem sucedida poderia ser justaposta à união muito mais problemática de Portugal e Espanha em 1580, como Astorga percebeu. Segundo Colbatch, o assunto tinha sido invocado também por aqueles que tentavam persuadir Vítor Amadeu II a não sair da Sabóia: "os Portugueses nutriam um ódio mortal pelos estrangeiros, e não tinham consentido este casamento imposto; e teriam manifestado outra vontade à morte do príncipe regente [D. Pedro]; e poderiam agir com ele como haviam feito com o rei de Espanha, isto é, privando-o da Coroa" 47.

As duas descrições antagónicas do sucesso ou insucesso das monarquias compósitas entrelaçam-se com vários temas centrais deste estudo. Vimos que a retórica dinástica da Sabóia defendia não só que a Casa gozava de estatuto real, mas também que o casamento português seria uma união entre iguais. Por outro lado, vista à luz da ansiedade sentida pelos portugueses em relação à sua independência, juntamente com a sua preocupação em proteger os seus domínios, a questão da paridade entre Sabóia e Portugal tornou-se controversa, exacerbada pelas leis de sucessão que regiam o trono português. Em virtude de uma provisão das Cortes de Lamego - um documento apócrifo ratificado em 1640 que teria regulado a sucessão em Portugal a partir de $1143-44^{48}$ - admitia-se a sucessão, quer por linha masculina, quer feminina, mas impedia as princesas herdeiras do trono de casar com estrangeiros. As Cortes portuguesas tinham concedido isenção

46 ASTo, Corte, MPRE, Lettere Ministri Spagna, m. 33, 198, Gubernatis ao ministro San Tommaso, 4 de Agosto de 1679.

47 COLBATCH, 1700, pp. 137-8.

48 Sobre esta matéria, veja-se o capítulo de I. Drumond Braga neste volume. 
da lei à infanta, o que não era suficiente para resolver as questões mais espinhosas do projecto nupcial. Por exemplo: onde viveria o casal, em Portugal ou na Sabóia? Que aconteceria se a infanta morresse antes de Vítor Amadeu II, ou se D. Pedro, ou mesmo Afonso VI, tivessem outros filhos? Vítor Amadeu seria rei? Qual seria o seu estatuto se da união nascessem filhos e fossem designados, por sua vez, herdeiros do trono português para além do saboiano? A Sabóia tornar-se-ia uma província de Portugal, política e economicamente? Estes pontos de debate dominaram as negociações sobre os termos do tratado matrimonial durante as missões de Gubernatis e Spinelli em Lisboa, ao longo dos anos 1678-7949. Um relatório de Gubernatis, por exemplo, reflectia sobre a questão da relação de poder, implícita até na ordem protocolar dos nomes e dos títulos:

"Acrescenta-se o título de Sua Alteza Real, igual ao do Rei Afonso, nomeado na dita escritura, mas ao nomear em primeiro lugar a Infanta ao falar-se do seu casamento com S.A.R., não houve remédio, dizendo que as Cortes tinham como primeiro objectivo casar a Infanta com o Duque de Sabóia e não o Duque de Sabóia com a Infanta. Contrapus-lhes eu que nas Capitulações se tinha sempre nomeado o Duque antes da Infanta." 50

Quando os vinte artigos do tratado de casamento foram finalmente sancionados a 14 de Maio de 1679, parecia que o ponto mais controverso tinha sido resolvido. Sobre a questão da paridade em matéria de protocolo epistolar, acentuava Gubernatis que o artigo $10^{\circ}$ estabelecia que os dois futuros soberanos fossem considerados iguais em todos os actos públicos, como se praticou no caso semelhante dos reis católicos D. Fernando e Isabel"51. Parecia ser uma comparação adequada, que servia como sumário idealizado

49 Ver, e.g., ASTo, Corte, MPRE, Lettere Ministri Portogallo, m. 3, fasc. 1, Correspondência de Spinelli; ASTo, Corte, MPRE, Negoziazioni col Portogallo, m. 1, fasc. 1, instruções a Gubernatis, 19 de Setembro de 1679; fasc. 2, "Memorie relative alla trattativa del matrimonio"; ASTo, Corte, MPRI, Matrimoni, m. 32, fasc. 26, Instruções a Spinelli, 1679.

50 ASTo, Corte, MPRI, Matrimoni, m. 32, fasc. 27, "Relatione del negotio sopra la Derogat. ne della legge di Lamego dal Conte di Gubnatoris", 1679.

51 CLARETTA, 1863, pp. 258-259. Ver também ASTo, Corte, MPRE, Lettere Ministri Portogallo, m. 3, fasc. 1, 14, Spinelli a Madame Real, 16 de Maio de 1678. 
dos objectivos que o casamento pretendia alcançar. Uma vez mais, as partes interessadas remetiam para o exemplo de uma união dinástica bem sucedida, tal como Guberantis fizera em Madrid. Se o tratado fosse cumprido, o casamento teria conduzido a uma união dinástica capaz de diluir as preocupações sentidas em Portugal e na Sabóia - no primeiro com o problema de garantir a sucessão e no segundo com a ausência de Vítor Amadeu II e com a natureza e a sobrevivência do seu título régio.

Todavia, o subtexto não pode ser ignorado: ambos os Estados olhavam o casamento com grande suspeição, o que, na realidade, provocou o fracasso do projecto. Nas palavras de Maria Francisca Isabel, o noivado entre os dois primos rompeu-se por causa das incertezas sobre a saúde de Vítor Amadeu II, difundidas em Portugal pelos relatórios de Cadaval. Se a doença era real ou simulada, como alguns suspeitavam, o ponto crucial é que tornou evidente a hostilidade sentida, quer na Sabóia, quer em Portugal, face à perspectiva de uma união dinástica. Uma carta do enviado extraordinário de Inglaterra em Lisboa, Charles Fanshawe, escrita pouco antes do rompimento do acordo, resume com clareza a posição de Cadaval, observando que se "era no início um grande promotor, tinha levantado tantas questões sobre as capacidades do Duque para o matrimónio, que as suas palavras tinham ofendido muito o ministro saboiano". Fanshawe acrescentava que "ambas as partes pareciam estar cansadas da questão que em pouco tempo será decidida porque os Portugueses sentem grande dor por terem a Princesa casada à pressa com ele [o duque de Sabóia] ou com outro" 52 . Pondo fim ao projecto, Maria Francisca Isabel informou a irmã da necessidade que tinha de responder às apreensões internas relativas ao futuro do trono português entregue um príncipe que parecia ser frágil. "Ela é filha do reino, tanto como é nossa", acrescentando que o céu tinha triunfado sobre a débil vontade humana ${ }^{53}$. Na sua resposta, também Maria Joana Baptista recorreu à Divina Providência, como explicação do que tinha acontecido, mas estava visivelmente amargurada pela oportunidade

52 CLARETTA, 1865, pp. 279-283. Veja-se também ASTo, Corte, MPRI, Lettere Principi Diversi, m. 83, Maria Francisca Isabel a Maria Joana Baptista, 20 de Novembro de 1682; TNA SP 89/15, Fanshawe a Jenkins, 23 de Novembro de 1682.

53 CLARETTA, 1865, p. 281. 
dinástica perdida que, para além de favorecer a Sabóia, teria levado "a grandeza Portuguesa mais longe do que alguma vez foi" 54 .

Com a ruptura final do projecto nupcial em finais de 1682, Portugal e a Sabóia ficaram ambos com dois herdeiros solteiros. A infanta recebeu numerosas propostas de casamento - o que se explica pela sua importância como herdeira presuntiva do trono de Portugal e pela existência de numerosos partidos qualificados na Europa - mas estava destinada a morrer solteira dezoito anos mais tarde. Em Abril de 1684, Vítor Amadeu II desposou por procuração a primeira das suas duas mulheres, Ana de Orleães (1669-1728), filha do duque de Orleães e sobrinha de Luís XIV. Seria tentador ver neste epílogo a confirmação da influência francesa na Sabóia. $\mathrm{Na}$ realidade, estava longe de ser o caso, pois o duque, liberto da regência da mãe, mostrou de imediato a sua vontade de autonomia em relação à França, tal como como tinha feito Maria Joana Baptista através das suas iniciativas diplomáticas. De facto, devemos ser prudentes com conclusões simplistas sobre o projecto matrimonial português, fundadas, afinal, na tradição historiográfica da imensa ambição de Maria Joana Baptista em perpetuar-se na regência ou, ainda, da sua arreigada dependência da França. Nem deveremos necessariamente considerar o malogro das núpcias com o que sabemos ter sido depois o papel histórico da Sabóia na história de Itália, uma identidade nacional que alguns viram prefigurada na oposição ao casamento e na tomada do poder pessoal por parte de Vítor Amadeu II. É bem mais adequado interpretar o plano à luz de um conjunto alternativo de razões históricas, de ambição dinástica e de responsabilidades e, como já vimos, compreender o seu fracasso como consequência das dificuldades inerentes a uma monarquia compósita. Voltando ao problema do espírito dinástico dos Sabóias, o casamento - "notre grand dessein" - era um puro arranjo familiar concebido pelas irmãs Sabóia-Nemours para servir os interesses fundamentais da Casa de Sabóia. Assim sendo, deverá ser situado no contexto de poder familiar, a começar pela forma como os ramos secundários se relacionavam com as casas dominantes, enquanto coligação de

54 ASTo, Corte, MPRE, Negoziazioni col Portogallo, m. 1, fasc. 2, Madame Real a Maria Francisca Isabel, 22 de Dezembro de 1682. 
interesses, para usar a expressão de Vester. Mais precisamente, o projecto era parte de uma estratégia de longo prazo, que recuava pelo menos até ao fim do século XVI, posta em prática pela Casa de Sabóia para demonstrar a sua superioridade sobre os rivais italianos e para assegurar o que considerava ser o seu lugar de direito entre as potências monárquicas que dirigiam a Europa. Do ponto de vista da Sabóia, as ligações genealógicas com Portugal eram parte integrante de tal estratégia e teriam sido renovadas com a união de Vítor Amadeu II e a infanta Isabel Luísa. Examinando as aspirações que estavam no âmago do projecto do casamento português, podemos então superar a historiografia do declínio ou da nascente identidade nacional que moldou os estudos sobre o Piemonte e a Sabóia, acentuando a lealdade dinástica e a aspiração à realeza que tanto consumiram os príncipes de Sabóia.

\section{Fontes e estudos}

\section{Fontes manuscritas}

Archivio di Stato di Torino, Corte

Materie politiche per rapporto all'estero (MPRE)

Lettere Ministri Francia: mazzi 108, 109.

Lettere Ministri Inghilterra: mazzi 4, 6, 7.

Lettere Ministri Portogallo: mazzi 2, 3.

Lettere Ministri Spagna: mazzi 33, 34.

Negoziazioni col Portogallo: mazzo 1.

Materie politiche per rapporto all'interno (MPRI)

Lettere Principi Diversi: mazzi 82, 83.

Lettere Principi Forestieri: mazzo 87.

Matrimoni: mazzo 32.

Storia della real casa di Savoia: Categoria 3, mazzo 20.

The National Archives, London

State Papers: 89/15, 92/13, 92/25, 104/188. 


\section{Fontes impressas}

ALBERI, E. (ed.) (1841), Le relazioni degli ambasciatori veneti al senato, serie II, vol. II. Firenze: Clio.

COLBATCH, John (1700), An Account of the Court of Portugal under the Reign of the Present King Dom Pedro II. London: Thomas Bennet.

DE BEAUCAIRE, Horric (ed.) (1898), Recueil des instructions données aux ambassadeurs et ministres de France depuis les traités de Westphalie jusqu'a la révolution française: Savoia-Sardaigne; Mantoue, 2 voll. Paris: Alcan (Felix) Librairie.

GUICHENON, Samuel (1660), Histoire Généalogique de la Royale Maison de Savoye, 2 vols. Lyon: Guillaume Barbier.

LETI, Gregorio (1684), Il teatro britannico, ò verò bistoria della Grande Brettagna, 5 vols. Amsterdam: Abramo Wolfgang.

POMPONNE, Nicolas Simon Arnauld (1860), Memoires du Marquis de Pomponne: ministre et secrétaire d'état au département des affaires étrangères. Paris: Benjamin Duprat.

\section{Estudos}

CARUTTI, Domenico (1875-80), Storia della diplomazia della corte di Savoia, 4 vols. Roma: Fratelli Bocca.

CARUTTI, Domenico (1883), Storia del regno di Vittorio Amedeo II. Firenze, Lemonnier, 1863.

CLARETTA, Gaudenzio (1865), Vita di Maria Francesca Elisabetta di Savoia-Nemours Regina di Portogallo. Torino: Eredi Botta.

CONTESSA, Carlo (1915), "Progetti economici della seconda Madama Reale fondati sopra un contratto di matrimonio, 1678-1682", Miscellanea di storia Italiana, ser. 3, 17, pp. 123-79.

CONTESSA, Carlo (1936), "La congiura del marchese di Parella (1682)", Bolletino Storico-Bibliografico Subalpino, XXXVIII, pp. 81-142.

DE MANNEVIlle, H. (1931), "Marie Françoise Elisabeth de Savoie-Nemours: une princesses française sur le trone de Portugal”, Revue d'bistoire diplomatique, 21, pp. 22-46, 193-217, 294-317.

DE SONNAZ, Gerbaix (1910), "Relazioni fra i reali di Savoia e i reali di Portogallo", Miscellanea di storia italiana, ser. III, XIV, pp. 100-199.

DÓRIA, Antonio Álvaro (1944), A Rainha D. Maria Francisca de Saboia. Porto: Livraria Civilização.

ELLIOTT, J. H. (1991), "The Spanish Monarchy and the Kingdom of Portugal, 1580-1640" in Conquest and Colaescence. The Shaping of the State in Early Modern Europe. Ed. Mark Greengrass. London: Edward Arnold.

ElliotT, J. H. (1992), “A Europe of Composite Monarchies”, Past and Present, 137, pp. 48-71.

FARGES, Louis (1907), "L'infante Isabelle de Portugal et ses dix-sept pretendants", Revue d'bistoire diplomatique, 21, pp. 355-77.

FERRERO LA MARMORA, Alberto (1862), Le vicende di Carlo di Simiane marchese di Livorno poi di Pianezza. Torino: Bocca.

FERRERO LA MARMORA, Alberto (1863), Notizie sulla vita e sulle geste militari di Carlo Emilio San Martino di Parella. Torino: Bocca. 
LOMBARDI, Giorgio (1986), "La Guerra del sale: Caleidoscopio di una Historia" in La guerra del sale (1680-1699): Rivolta e frontiere del Piemonte barocco. Ed. Giorgio Lombardi. Milano: Angeli.

ORESKO, Robert (1997), "The House of Savoy in search for a royal crown in the seventeenth century" in Royal and Republican Sovereignty in Early Modern Europe. Essays in Memory of Ragnhild Hatton. Eds. Graham Gibbs, Robert Oresko and Hamish Scott. Cambridge: Cambridge University Press.

ORESKO, Robert (2004), "Maria Giovanna Battista of Savoy-Nemours (1644-1724): daughter, consort, and regent of Savoy" in Queenship in Europe 1660-1815. The role of the consort. Ed. Clarissa Campbell Orr. Cambridge: Cambridge University Press.

OSBORne, Toby (2002), Dynasty and Diplomacy in the Court of Savoy. Political Culture and the Thirty Years War. Cambridge: Cambridge University Press.

OSBORNE, Toby (2007), "The Surrogate War between the Savoys and the Medici: Sovereignty and Precedence in Early Modern Italy", The International History Review, XXIX, pp. 1-21.

ROUSSETT, Camille (1861-3), Histoire de Louvois et de son administration politique et militaire. 3 vols. Paris: Didier.

SPAGNOLETTI, Angelantonio (2003), Le dinastie italiane nella prima età moderna. Bologna: Il Mulino.

SYMCOX, Geoffrey (1983), Victor Amadeus II: Absolutism in the Savoyard State 1675-1730. London: Thames and Hudson.

SYMCOX, Geoffrey (2002), "La reggenza della seconda madama reale (1675-84)" in Storia di Torino IV. La città fra crisi e ripresa (1630-1730). Ed. Giuseppe Ricuperati. Torino: Einaudi.

VESTER, Matthew A. (2008), Jacques de Savoie-Nemours: L'apanage du Genevois au coeur de la puissance dynastique savoyarde au XVIe siècle. Genéve: Droz. 